\title{
Radical sternectomy and primary musculocutaneous flap reconstruction to control sternal osteitis
}

\author{
R. Wettstein, MD \\ D. Erni, $M D^{a}$ \\ P. Berdat, $M D^{b}$ \\ D. Rothenfluh ${ }^{\mathrm{a}}$ \\ A. Banic, MD, $\mathrm{PhD}^{\mathrm{a}}$
}

From the Division of Plastic Surgery a and the Department of Cardiovascular Sur-

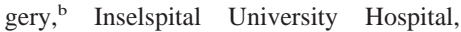
Berne, Switzerland.

Received for publication May 3, 2001; revisions requested Sept 12, 2001; revisions received Oct 2, 2001; accepted for publication Oct 24, 2001.

Address for reprints: Dominique Erni, MD, Division of Plastic Surgery, Inselspital University Hospital, CH-3010 Berne, Switzerland (E-mail: dominique.erni@insel.ch).

J Thorac Cardiovasc Surg 2002;123: 1185-90

Copyright (C) 2002 by The American Association for Thoracic Surgery

0022-5223/2002 \$35.00+0 12/1/121304

doi: $10.1067 / \mathrm{mtc} .2002 .121304$
Objective: Sternal osteitis after median sternotomy is associated with considerable morbidity and mortality. The use of muscle and omentum flaps has been proved as valid adjunct to combat these severe infections. In this study we present our experience with a more radical approach.

Methods: Sternectomy consisted of the resection of the entire sternum, including the costochondral arches and the sternoclavicular joints, and was followed by the repair of the defect with musculocutaneous flaps without any restabilization of the thoracic wall. Thirteen patients received a vertical rectus abdominis musculocutaneous flap, 14 patients received a pedicled latissimus dorsi musculocutaneous flap, and 12 patients received a free latissimus dorsi musculocutaneous flap (total of 40 flaps in 39 patients of 66 patients who required surgical revision for sternal osteitis of 6078 total patients with sternotomies).

Results: Two patients died within 30 days after the operation (early mortality of $5.1 \%$ ) however, they did not die of sternal infection, which was cured without any recurrence in all cases. Seventeen patients (44\%) required secondary, mostly minor operations for local complications. Despite some paradoxic chest movements, the patient satisfaction rating was unanimously high at the long-term follow-up ( 0.4 to 8.5 years, median 2.3 years). The short- and long-term complication rates were similar in the three groups.

Conclusion: We conclude that radical sternectomy and immediate musculocutaneous flap repair provided definitive control of sternal infection in even the most severe cases, thus reducing infection-related mortality. The trade-off was a substantial rate of local complications; however, these did not cause any relevant morbidity.

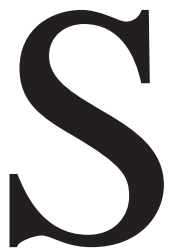

ince the introduction of sternotomy in 1957, sternal wound infection has been an infrequent but challenging problem with considerable mortality and morbidity. ${ }^{1-3}$ Débridement and open packing was the only treatment option available until continuous antibiotic irrigation, which allowed for refixation of the sternum, was introduced. ${ }^{4}$ This strategy led to a dramatic reduction in mortality, although hospital stay was still prolonged and morbidity remained high. ${ }^{5,6}$ For patients unresponsive to débridement and closed catheter irrigation, Lee and associates ${ }^{7}$ described the concept of sternal excision, transposition of the well-vascularized omentum, and primary closure. Jurkiewicz and colleagues ${ }^{8}$ expanded the concept by using a pectoralis major muscle flap, thus achieving further reductions in mortality and hospital stay.

During the past 20 years, the pectoralis major muscle has become the flap of choice for the treatment of sternal osteitis. ${ }^{9-11}$ The omentum or other muscles, such as the rectus abdominis and latissimus dorsi muscles, represent alternative op- 

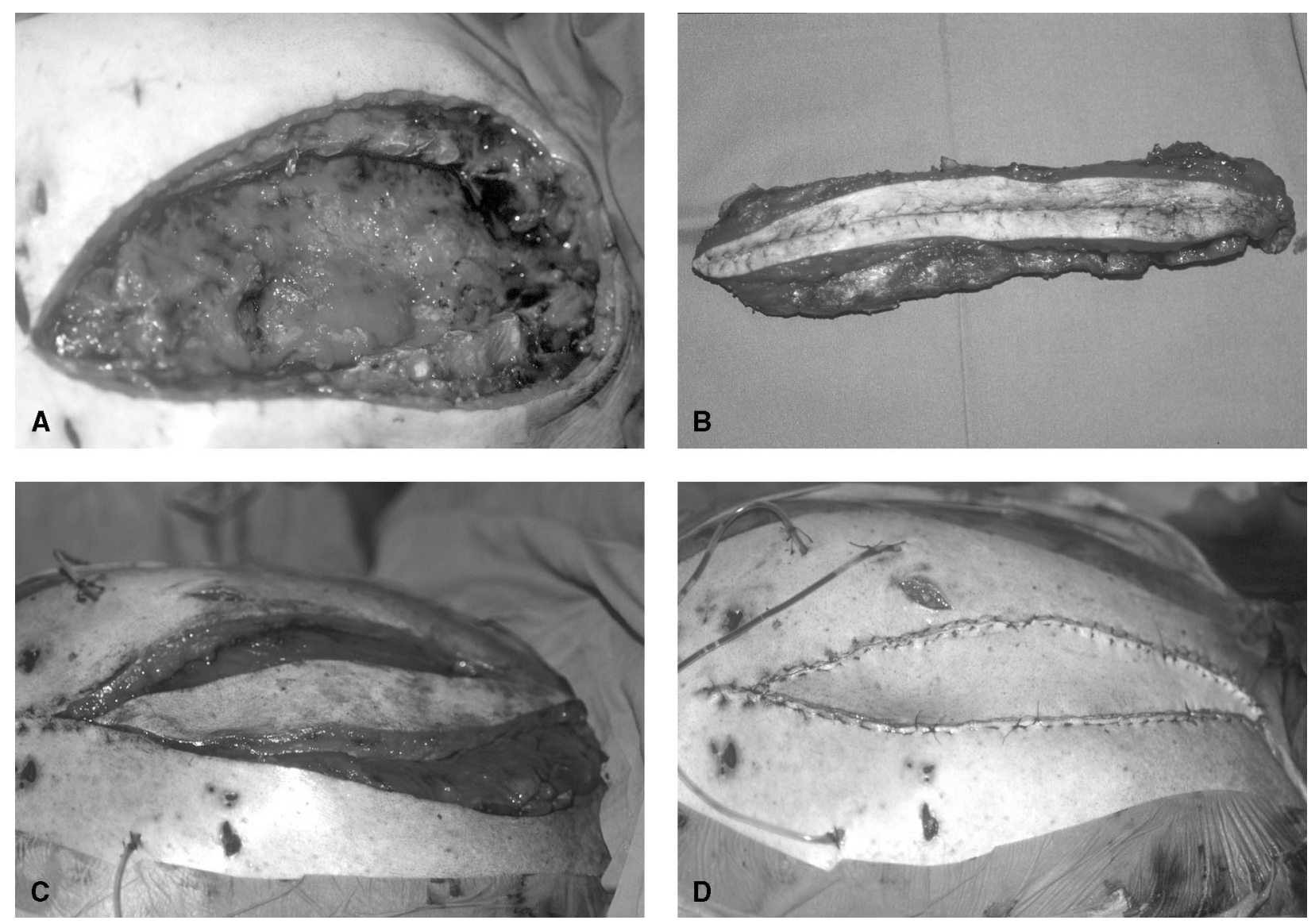

Figure 1. A, Large defect of thoracic wall and soft tissues results after radical resection of entire infected sternum, including affected overlying muscle and skin (B). C, Thoracic wall defect is reconstructed with muscle part of free latissimus dorsi musculocutaneous flap. D, Skin paddle provides sufficient tissue to avoid tension as well as dead space between reconstructed thoracic wall and skin.

tions. . $^{70,12-17}$ Nevertheless, early mortalities between $2 \%$ and $10.9 \%$ were described in the largest series to evaluate the outcome of the infected sternum after débridement followed by muscle flap coverage, ${ }^{9-11,18}$ with most deaths related to a persistent infection with subsequent mediastinitis and sepsis. Under the assumption that insufficient débridement might promote recurrent infection, we have started to resect the sternum routinely in a radical manner to treat severe and recalcitrant infections. ${ }^{19}$

To reconstruct such a large defect (Figure 1), muscular or omental flaps do not provide sufficient amounts of tissue. Various flaps may be combined ${ }^{9,10}$; however, this is more invasive and causes additional morbidity. Moreover, tension-free skin closure may not be possible or may produce a tenting phenomenon that results in a dead space that is prone toward infection. To achieve adequate chest wall repair, we prefer to use musculocutaneous flaps, such as the vertical rectus abdominis musculocutaneous flap and the pedicled and free latissimus dorsi flaps.

The aim of this study was to analyze our results obtained with radical sternectomy followed by immediate reconstruction with musculocutaneous flaps. In particular, it was our intention to determine whether recalcitrant sternal osteitis and subsequent mortality might in fact be reduced with this concept, and to evaluate the complications related to the three different flaps. Furthermore, we wanted to analyze the long-term results after extended sternectomy without restabilization of the thoracic wall.

\section{Patients and Methods}

Thirty-nine consecutive patients undergoing radical sternectomy and immediate primary musculocutaneous flap reconstruction between May 1991 and August 2000 were included in this study. One patient required a second flap because of a partial failure of the primary reconstruction. The vertical rectus abdominis musculocutaneous flap was used in 13 cases, the pedicled latissimus dorsi musculocutaneous flap was used in 15 cases, and the free latissimus dorsi musculocutaneous flap was used in 12 cases. The patients were recruited from 66 patients who required a revisionary operation because of sternal osteitis after cardiac surgery $(\mathrm{n}=$ 6078 patients, incidence $1.1 \%$ ) during the study period. The pa- 
TABLE 1. Patient data

\begin{tabular}{|c|c|c|c|}
\hline & $\begin{array}{l}\text { Vertical rectus abdominis } \\
\text { musculocutaneous flap } \\
\text { (n=13) }\end{array}$ & $\begin{array}{c}\text { Pedicled latissimus dorsi } \\
\text { musculocutaneous } \\
\text { flap ( } \mathrm{n}=15 \text { ) }\end{array}$ & $\begin{array}{l}\text { Free latissimus dorsi } \\
\text { musculocutaneous } \\
\text { flap ( } n=12 \text { ) }\end{array}$ \\
\hline \multicolumn{4}{|l|}{ Age (y) } \\
\hline Range & $58-77$ & $52-78$ & $57-74$ \\
\hline Median & 69 & 68 & 65 \\
\hline \multicolumn{4}{|l|}{ Follow-up (y) } \\
\hline Range & $0.4-2.1$ & $0.6-8.5$ & $2.2-7.7$ \\
\hline Median & 1.5 & 1.8 & 5.1 \\
\hline \multicolumn{4}{|l|}{ Gender (No.) } \\
\hline Male & 11 & 13 & 10 \\
\hline Female & 2 & 2 & 2 \\
\hline \multicolumn{4}{|l|}{ Initial heart operation (No.) } \\
\hline $\begin{array}{l}\text { Coronary artery bypass } \\
\text { grafting }\end{array}$ & 11 & 14 & 11 \\
\hline Valvular repair & 2 & 2 & 1 \\
\hline \multicolumn{4}{|l|}{ Risk factors (No.) } \\
\hline Diabetes mellitus & 5 & 9 & 3 \\
\hline Arterial hypertension & 11 & 10 & 7 \\
\hline Smoking & 7 & 9 & 5 \\
\hline Heart failure & 7 & 10 & 4 \\
\hline Obesity & 2 & 4 & 1 \\
\hline \multicolumn{4}{|l|}{ Previous interventions (No.) } \\
\hline Total & 6 & 9 & 6 \\
\hline Muscle flap & 1 & 4 & 3 \\
\hline Sternal refixation & 2 & 3 & 3 \\
\hline Catheter irrigation & 5 & 3 & 6 \\
\hline
\end{tabular}

tients' data are summarized in Table 1. Radical sternectomy with flap reconstruction was performed as a primary procedure in 19 patients, whereas the other 20 patients (including the patient who required a second flap) had undergone one or more previous interventions related to sternal osteitis, including muscle flap coverage $(n=7)$, débridement and refixation of the sternum $(n=7)$, and catheter irrigation $(\mathrm{n}=14)$.

Sternal osteitis was diagnosed by clinical examination (local infection signs, fistulas, fever), computed tomographic scan (dehiscence or osteolysis of the sternum, retrosternal fluid collection), and laboratory analysis (leukocytosis, C-reactive protein increase). The diagnosis was verified by microbiologic examination and histologic analysis in all cases. Radical sternectomy was performed in cases of persistent sternal osteitis after previous débridement, refixation, and catheter irrigation, or when stable refixation could not be achieved with the parts of the sternum remaining after conventional débridement. The resection included the costochondral arches and the sternoclavicular joints, as well as any affected overlying muscle, fat, and skin.

The right vertical rectus abdominis musculocutaneous flap was the flap of choice, provided the right internal thoracic artery and vein were intact and abdominal hernias and horizontal abdominal scars were absent. A vertical skin paddle of the size of the sternal soft tissue defect was dissected over the right rectus abdominis muscle (usually about $25 \times 7 \mathrm{~cm}$ ). The anterior rectus sheath was incised, leaving a cuff of approximately 2 to $3 \mathrm{~cm}$ width, which contained the most competent muscle perforators supplying the skin paddle. The entire rectus abdominis muscle was dissected free from the surrounding sheaths, and the caudal muscle insertion was transected after ligation of the inferior epigastric vessels. After transection of the lateral parts of the cephalad muscle insertion, the flap, pedicled on the superior epigastric vessels, could easily be rotated into the defect. A large suction drain was placed between the flap and the mediastinum, and the flap muscle was adapted to the edges of the thoracic wall. Skin closure was performed in two layers after the insertion of two suction drains on each side of the skin paddle. The anterior rectus sheath was closed with running Everett sutures with a nonresorbable material. After the operation, an abdominal garment was prescribed for 6 weeks.

A musculocutaneous latissimus dorsi musculocutaneous flap was used if a vertical rectus abdominis musculocutaneous flap was not available. In the case of critically ill patients, a pedicled flap transfer (pedicled latissimus dorsi musculocutaneous flap) was chosen in order to reduce operative time; otherwise, a free flap transfer (free latissimus dorsi musculocutaneous flap) was preferred. In both techniques, a skin island over the latissimus dorsi muscle was designed. As determined by the arch of rotation of the flap pedicle, the skin paddle was placed more caudally in the pedicled flap than in the free flap. The entire muscle was raised, pedicled on the thoracodorsal vessels, which were transected in the free latissimus dorsi musculocutaneous flap to be reanastomosed to the vessels at the site of the defect. The surgical technique has previously been described in detail elsewhere. ${ }^{19}$ The superior thyroid artery $(n=4)$, the internal thoracic artery $(n=4)$, the inferior thyroid artery $(n=3)$, the common carotid artery $(n=1)$, the superior thyroid vein $(n=4)$, the internal thoracic vein $(n=$ $4)$, and the external jugular vein $(n=4)$ served as recipient vessels. The free latissimus dorsi musculocutaneous flap was moni- 
TABLE 2. Mortality and postoperative course

\begin{tabular}{|c|c|c|c|}
\hline & $\begin{array}{l}\text { Vertical rectus abdominis } \\
\text { musculocutaneous flap } \\
\text { (n=13) }\end{array}$ & $\begin{array}{l}\text { Pedicled latissimus dorsi } \\
\text { musculocutaneous } \\
\text { flap (n=15) }\end{array}$ & $\begin{array}{l}\text { Free latissimus dorsi } \\
\text { musculocutaneous } \\
\text { flap ( } n=12 \text { ) }\end{array}$ \\
\hline \multicolumn{4}{|l|}{ Mortality (No.) } \\
\hline Total & 2 & 0 & 4 \\
\hline Early & 1 & 0 & 1 \\
\hline Infection related & 0 & 0 & 0 \\
\hline Recurrent infection (No.) & 0 & 0 & 0 \\
\hline \multicolumn{4}{|l|}{ Extubation time (d) } \\
\hline Range & $0-22$ & $0-23$ & $0-17$ \\
\hline Median & 1 & 1 & 1 \\
\hline \multicolumn{4}{|l|}{ Intensive care (d) } \\
\hline Range & $1-27$ & $1-24$ & $0-20$ \\
\hline Median & 1 & 2 & 1 \\
\hline \multicolumn{4}{|l|}{ Hospitalization (d) } \\
\hline Range & $15-96$ & 13-204 & $13-48$ \\
\hline Median & 23 & 27 & 23 \\
\hline
\end{tabular}

tored by clinical and temperature control, and $6 \%$ dextran 70 at 50 $\mathrm{mL} / \mathrm{h}$ was given to protect the microvascular anastomoses until 4 days after the operation.

Postoperative extubation was performed according to conventional guidelines. All the patients were allowed to recover in the intensive care unit. Mobilization and respiratory physiotherapy were initiated as soon as the patient was extubated. Specific antibiotic treatment was given for 2 months to patients operated on before 1995; this duration was reduced to 2 weeks after 1995.

The objective data were obtained from reviewing the hospital charts. The long-term follow-up consisted of telephone interviews of the patients and their primary care physicians. The patients were asked to comment on their general satisfaction, chest wall pain at rest and during physical activity, the need for pain medication, rubbing and clicking of the edges of the osseous thoracic wall, restriction of daily activities as a result of respiratory insufficiencies, and physical condition compared to that before the operation. Primary care physicians were questioned about any reoperations for recurrent sternal wound complications at another institution.

\section{Results}

Six patients had died at the time of the long-term follow-up (15.4\%; Table 2). Two of them had died within 30 days after the operation ( $5.1 \%$ early mortality), 1 of acute renal and cardiac failure and the other of hemothorax of unknown origin. The other patients died of myocardial ischemia $(\mathrm{n}=$ $2)$, stroke $(n=1)$, and malignant disease $(n=1)$. None of the deaths were related to sternal infection or mediastinitis, which were definitively cured by the operation in all cases. Twenty-six patients could be extubated in the operating room or within the first 24 hours after the operation and were allowed to be transferred to the ward the day after the operation. Intubation and intensive care unit stay were prolonged for longer than 3 days after the operation for cardiovascular reasons $(n=4)$, renal failure $(n=1)$, persistent systemic inflammatory response syndrome $(\mathrm{n}=1)$, and respiratory distress related to paralysis of the phrenic nerve and myasthenia gravis $(\mathrm{n}=1)$. Coughing and pressing produced a variable degree of paradoxic chest movement, which required some external pressure on the flap during the first postoperative days. Only the patient with the phrenic nerve palsy and myasthenia gravis required a thoracic wall reconstruction with alloplastic material. The postoperative hospitalization ranged from 13 to 204 days (median 24 days). The complications described previously were similar in all three groups.

Nineteen local wound healing complications necessitating reintervention (48\%) occurred in 17 patients $(44 \%$; Figure 2). In 2 cases, the aortocoronary bypass graft was injured during sternectomy and needed revision. One patient sustained a partial loss of the vertical rectus abdominis musculocutaneous flap as the result of an intraoperative injury of the internal thoracic artery and received a pedicled latissimus dorsi musculocutaneous flap transfer 4 days later. Three patients wanted to have the skin paddle excised for esthetic reasons.

In the long-term follow-up, patient satisfaction was unanimously high (Figure 3). Five patients reported some discomfort in the chest at rest without precise localization. Nine patients had minor pain during physical activity. However, only 2 patients occasionally used analgesics for chest wall pain. Rubbing and clicking occurred in 9 cases, most often when the patient rolled over in bed. None of the patients reported reduced physical activity related to sternal instability. No patient required further corrective surgery at another institution. The long-term difficulties were similar in the three groups.

\section{Discussion}

The principal finding of this study was that sternal infection and mediastinitis were definitively cured in all the patients treated with radical sternectomy and musculocutaneous flap 
coverage, thus preventing any subsequent infection-related morbidity and mortality. In the literature, recurrent infection is reported to occur in $22 \%$ to $52 \%$ of cases after débridement, sternal refixation, and mediastinal catheter irrigation $18,20,21$ and in $3 \%$ to $26 \%$ of cases after débridement, sternal refixation, and muscle flap coverage. ${ }^{9-11,18,22}$ The early mortality is strongly determined by the control of sternal infection. Early mortality was $5.1 \%$ in our series, compared to rates as great as $30 \%$ after débridement, sternal refixation, and mediastinal catheter irrigation 6 and rates of $2 \%$ to $10.9 \%$ after débridement, sternal refixation, and muscle flap coverage. ${ }^{9-11,18,22}$ Most importantly, none of the deaths in our series were caused by a recurrent sternal infection or mediastinitis, which was not the case in the other studies.

These data are in accordance with the common opinion that failure of infection control is a consequence of insufficient débridement and persistent infection of bone, cartilage, or foreign bodies, ${ }^{10}$ which is consequently prevented by the radical débridement of the sternum as performed in our cases. The trade-offs for the consistent infection control are the unstable thoracic wall, the increased operating time, and the creation of a large donor site defect caused by harvesting the musculocutaneous flap needed for the repair of the thoracic wall.

However, most of the patients could be extubated immediately after the operation or shortly thereafter, just as after more conservative operative interventions for sternal infection. ${ }^{10,22}$ Extubation time and intensive care course suggest that the patients tolerated the invasive procedure well. The postoperative complications were rather to wound healing problems related than to the recovery of the general condition. The complication rate was higher than described after sternal débridement, refixation, and muscle flap coverage. ${ }^{9,22}$ This may be related to the negative selection of our patients, who represented the most severe cases of infection. However, the surgical revisions required for treating the complications described in this study were performed in patients in stable condition and healed from sternal infection and mediastinitis. In addition, the complications did not seem to affect the hospital stays of our patients, which were similar to those described for less invasive procedures and appeared to be influenced mainly by the control of the infection.9,13,23 The hospitalization time may be further diminished by the home use of intravenous antibiotic therapy, ${ }^{9}$ a technique not used in our series.

Some complications were related to the type of the musculocutaneous flap used. Latissimus dorsi musculocutaneous flaps are notorious for seroma formation, an annoying complication that rarely occurs after vertical rectus abdominis musculocutaneous flap operations. Despite the technically more challenging and time-consuming technique, the free transfer of the latissimus dorsi musculocutaneous

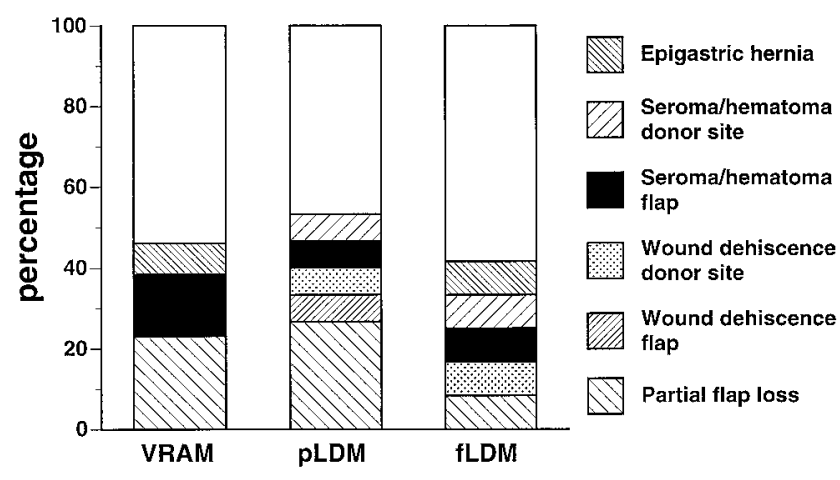

Figure 2. Local complications necessitating surgical revision after radical sternectomy and chest wall repair with vertical rectus abdominis musculocutaneous flap (VRAM, $n=13$ ), pedicled latissimus dorsi musculocutaneous flap ( $p L D M, n=15)$ and free latissimus dorsi musculocutaneous flap ( $f L D M, n=12$ ). Complications included epigastric hernia (down and right pointing narrow diagonally filled bars), seroma or hematoma of donor site (up and right pointing wide diagonally filled bars), seroma or hematoma of flap (black bars), wound dehiscence at donor site (dotted bars), wound dehiscence at flap (up and right pointing narrow diagonally filled bars), and partial flap loss (down and right pointing wide diagonally filled bars).

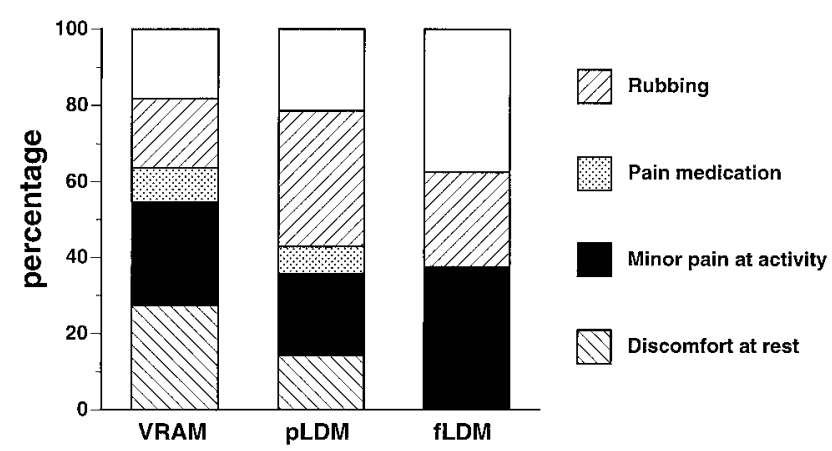

Figure 3. Long-term follow-up after radical sternectomy and chest wall repair with vertical rectus abdominis musculocutaneous flap (VRAM, $n=11$ ), pedicled latissimus dorsi musculocutaneous flap ( $p L D M, n=14$ ) and free latissimus dorsi musculocutaneous flap ( $f L D M, n=8$ ). Negative reports included rubbing (up and right pointing diagonally filled bars), pain medication requirement (dotted bars), minor pain at activity (black bars), and discomfort at rest (down and right pointing diagonally filled bars).

flap appears to cause less partial flap failure than does the pedicled transfer. This, however, may also be influenced by a certain selection bias in our series, because the critically ill patients were excluded from receiving a free latissimus dorsi musculocutaneous flap.

Some concerns may arise about harvesting the rectus abdominis muscle for flap reconstruction of the destabilized thoracic wall. Weakening and injuring of the abdominal wall may hamper spontaneous breathing, thus resulting in 
pulmonary complications and delayed recovery. In our series, however, intubation time, duration of intensive care, and hospital stay were not extended after vertical rectus abdominis musculocutaneous flap operations relative to latissimus dorsi musculocutaneous flap operations. Another concern may be related to the surgical approach for late cardiac interventions, which necessitates remobilization of the flap on the side opposite to its vascular pedicle.

In the long term, patient satisfaction was unanimously high despite some paradoxic chest wall movement, which, however, did not seem to impair daily activity. Kohman and associates ${ }^{24}$ were unable to demonstrate any significant difference in late pulmonary function between normal sternotomy and sternectomy without stabilization of the thoracic wall. Moreover, the larger gap of the thoracic wall caused by a more radical sternectomy may prevent painful rubbing and clicking of the bony edges, which was less frequent in our series than has been reported after more conservative

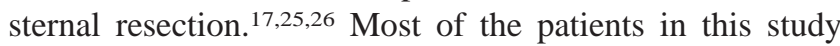
were not concerned about the esthetic aspect of the skin paddle or the increased scar length.

To our knowledge, this is the first study to present a consecutive series of patients undergoing radical sternectomy and musculocutaneous flap reconstruction. The interpretation of our results may be limited by the retrospective nature of the analysis and the extended period of data assessment, during which adjunct treatment modalities (eg, anesthetic techniques, intensive care management, and antibiotic treatment) have significantly improved. With the concept presented in this study, however, a consistent cure and prevention from subsequent infection-related morbidity and mortality were achieved even in the subset of the most severe, recalcitrant cases of sternal osteitis, and with an acceptable rate of complications. This justifies the invasive nature of the procedure and suggest its application not only as a salvage operation for failures after previous interventions but also as a primary approach for severe sternal osteitis.

We thank Dr Stacy S. Wu for her assistance in finalizing this article.

\section{References}

1. Julian OC, Lopez-Belio M, Dye WS, Javid H, Grove WJ. Appraisal of progress in surgical therapy. Surgery. 1957;42:753-61.

2. Blanchard A, Hurni M, Ruchat P, Stumpe F, Fischer A, Sadeghi H. Incidence of deep and superficial sternal infection after open heart surgery: a ten years retrospective study from 1981 to 1991. Eur J Cardiothorac Surg. 1995;9:153-7.

3. Risk factors for deep sternal wound infection after sternotomy: a prospective, multicenter study. J Thorac Cardiovasc Surg. 1996;111: $1200-7$.

4. Shumacker HB, Mandelbaum I. Continuous antibiotic irrigation in the treatment of infection. Arch Surg. 1968;86:54-7.

5. Bryant LR, Spencer FC, Trinkle JK. Treatment of median sternotomy infection by mediastinal irrigation with an antibiotic solution. Ann Surg. 1969;169:914-20.
6. Serry C, Bleck PC, Javid H, Hunter JA, Goldin MD, DeLaria GA, et al. Sternal wound complications: management and results. J Thorac Cardiovasc Surg. 1980;80:861-7.

7. Lee AB, Schimert G, Shaktin S, Seigel JH. Total excision of the sternum and thoracic pedicle transposition of the greater omentum: useful stratagems in managing severe mediastinal infection following open heart surgery. Surgery. 1976;80:433-6.

8. Jurkiewicz MJ, Bostwick J, Hester TR, Bishop JB, Craver J. Infected median sternotomy wound. Successful treatment by muscle flaps. Ann Surg. 1980;191:738-44.

9. Jones G, Jurkiewicz MJ, Bostwick J, Wood R, Bried JT, Culbertson J, et al. Management of the infected median sternotomy wound with muscle flaps: the Emory 20-year experience. Ann Surg. 1997;225:76676.

10. Pairolero PC, Arnold PG, Harris JB. Long-term results of pectoralis major muscle transposition for infected sternotomy wounds. Ann Surg. 1991;213:583-9.

11. Shafir R, Weiss J, Gur E, Herman O, Siegman-Igra Y, Sorkine P, et al. Sternal wound infection: our experience with 200 cases. J Cardiovasc Surg (Torino). 1994;35:103-4.

12. Tizian C, Borst HG, Berger A. Treatment of total sternal necrosis using the latissimus dorsi muscle flap. Plast Reconstr Surg. 1985;76: 703-7.

13. Weinzweig N, Yetman R. Transposition of the greater omentum for recalcitrant median sternotomy wound infections. Ann Plast Surg. 1995:34:471-7.

14. Herrera HR, Ginsburg ME. The pectoralis major myocutaneous flap and omental transposition for closure of infected median sternotomy wounds. Plast Reconstr Surg. 1982;70:465-70.

15. Nahai F, Rand RP, Hester TR, Bostwick J, Jurkiewicz MJ. Primary treatment of the infected sternotomy wound with muscle flaps: a review of 211 consecutive cases. Plast Reconstr Surg. 1989;84:43441.

16. Moor EV, Neuman RA, Weinberg A, Wexler MR. Transposition of the great omentum for infected sternotomy wounds in cardiac surgery: report of 16 cases and review of published reports. Scand J Plast Reconstr Surg Hand Surg. 1999;33:25-9.

17. Fansa H, Handstein S, Schneider W. Treatment of infected median sternotomy wounds with a myocutaneous latissimus dorsi muscle flap. Scand Cardiovasc J. 1998;32:33-9.

18. Borger MA, Rao V, Weisel RD, Ivanov J, Cohen G, Scully HE, et al. Deep sternal wound infection: risk factors and outcomes. Ann Thorac Surg. 1998;65:1050-6.

19. Banic A, Ris HB, Erni D, Striffeler H. Free latissimus dorsi flap for chest wall repair after complete resection of infected sternum. Ann Thorac Surg. 1995;60:1028-32.

20. Grossi EA, Culliford AT, Krieger KH, Kloth D, Press R, Baumann FG, et al. A survey of 77 major infectious complications of median sternotomy: a review of 7,949 consecutive operative procedures. Ann Thorac Surg. 1985;40:214-23.

21. Berg HF, Brands WG, van Geldorp TR, Kluytmans-VandenBergh FQ, Kluytmans JA. Comparison between closed drainage techniques for the treatment of postoperative mediastinitis. Ann Thorac Surg. 2000; 70:924-9.

22. Hugo NE, Sultan MR, Ascherman JA, Patsis MC, Smith CR, Rose EA. Single-stage management of 74 consecutive sternal wound complications with pectoralis major myocutaneous advancement flaps. Plast Reconstr Surg. 1994;93:1433-41.

23. Jeevanandam V, Smith CR, Rose EA, Malm JR, Hugo NE. Singlestage management of sternal wound infections. J Thorac Cardiovasc Surg. 1990;99:256-62.

24. Kohman LJ, Auchincloss JH, Gilbert R, Beshara M. Functional results of muscle flap closure for sternal infection. Ann Thorac Surg. 1991; 52:102-6.

25. Ringelman PR, Vander Kolk CA, Cameron D, Baumgartner WA, Manson PN. Long-term results of flap reconstruction in median sternotomy wound infections. Plast Reconstr Surg. 1994;93:1208-14.

26. Yuen JC, Zhou AT, Serafin D, Georgiade GS. Long-term sequelae following median sternotomy wound infection and flap reconstruction. Ann Plast Surg. 1995;35:585-9. 